Supporting Information for:

\title{
Temperature Sensing of Thiolate Addition by Phenolate Merocyanine Dyes: Importance of the Quinone Methide Resonance Structure
}

Abigail J. Van Riesen, Ryan E. Johnson, M. Sameer Al-Abdul-Wahid, Cristina Liota, Anjelyn Christyanton, and Richard A. Manderville*

\section{Table of Contents:}

1. Figure S1. UV-vis $\mathrm{p} K_{\mathrm{a}} \mathrm{s}$ for phenolic MC dyes.

2. Figure S2. UV-vis of MC dyes in absence and presence of 25 equiv. NaSMe.

3. Figure S3. ${ }^{1} \mathrm{H}$ NMR spectrum of PhOBtz•SMe $(20 \mathrm{mM})$ at $241 \mathrm{~K}$.

4. Figure S4. NMR spectra of PhOBtz•SMe at $298 \mathrm{~K}$.

5. Figure S5. COSY NMR spectrum PhOHBtz $(1 \mathrm{mM})+5$ equiv. NaSMe at $241 \mathrm{~K}$.

S7

6. Figure S6. ${ }^{1} \mathrm{H}$ NMR spectra of $\mathrm{PhOBtz}$ from $\mathrm{SMe}$ vs. $\mathrm{NaCO}_{3}$ addition.

7. Figure S7. ${ }^{1} \mathrm{H}$ NMR spectra of PhOBtz as a function of temperature.

S9

8. Figure S8. ${ }^{1} \mathrm{H}$ NMR for relative ratios of PhOBtz vs. PhOBtz•SMe.

9. Figure S9. NMR spectra of PhOHBtz.

10. Figure S10. NMR spectra of PhOMeBtz.

11. Figure S11. NMR spectra of $\mathrm{PhNMe} 2 \mathrm{Btz}$.

12. Figure S12. NMR spectra of CIPhOHBtz. 
A)

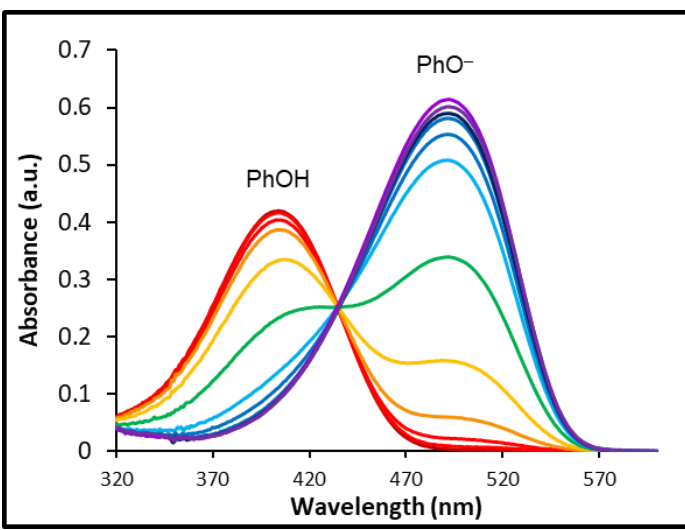

B)

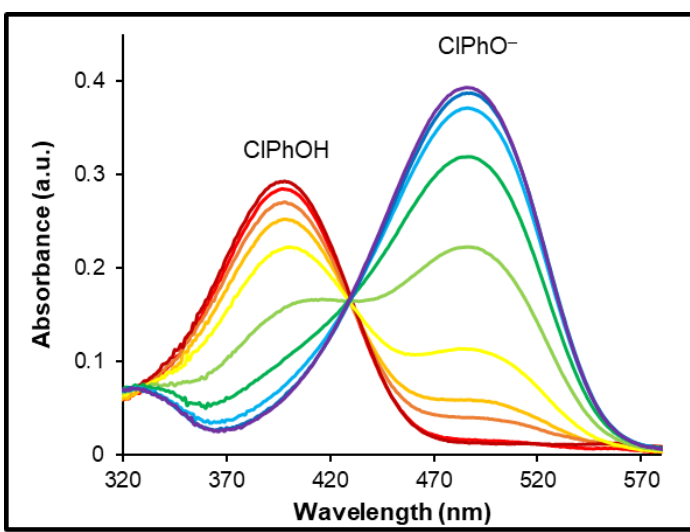

C)

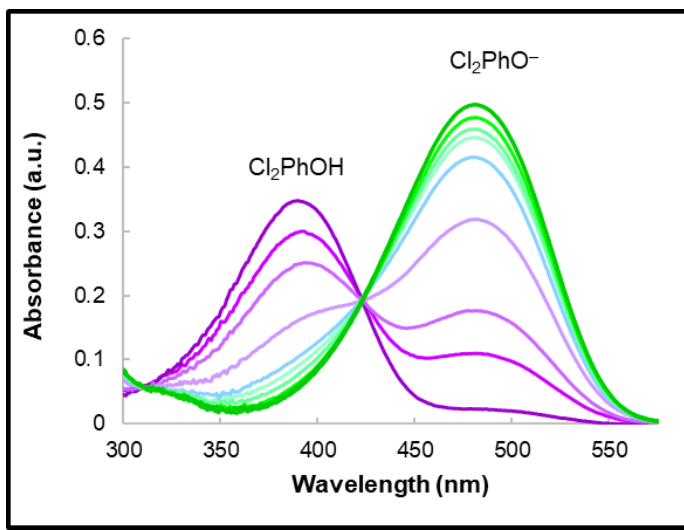

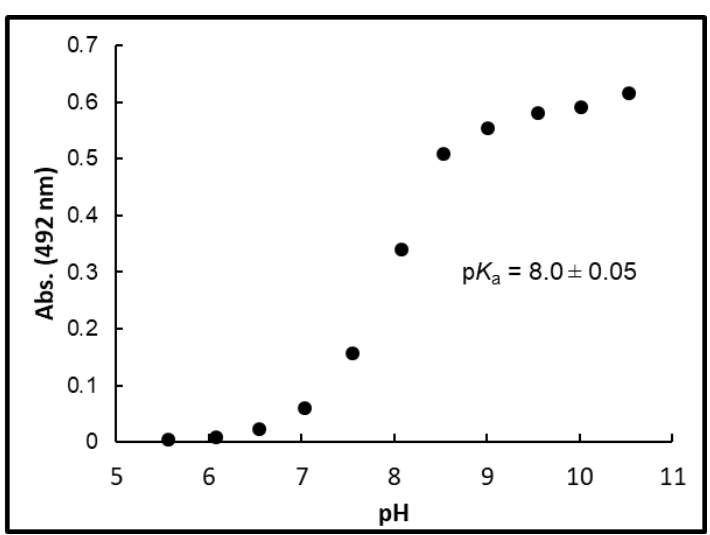
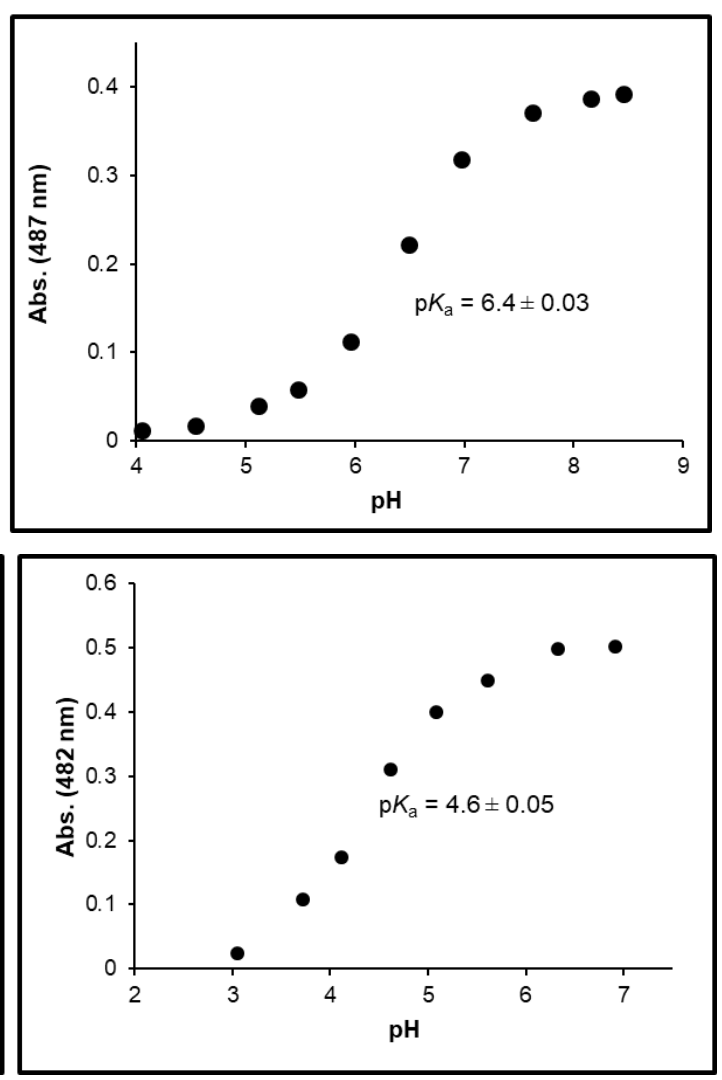

Figure S1. UV-vis absorption spectra of the phenolic dyes $(10 \mu \mathrm{M})$ as a function of $\mathrm{pH}$ in aqueous buffer $(0.05 \mathrm{M}$ containing $0.2 \mathrm{M} \mathrm{KCl})$ at $21^{\circ} \mathrm{C}$ and plots of phenolate absorbance as a function of $\mathrm{pH}$; A) PhOHBtz, $\mathrm{p} K_{\mathrm{a}}=8.0$, B) $\mathrm{ClPhOHBtz}, \mathrm{p} K_{\mathrm{a}}=6.4$, C) $\mathrm{Cl}_{2} \mathrm{PhOHBtz}, \mathrm{p} K_{\mathrm{a}}=4.6$.

S2 
A)

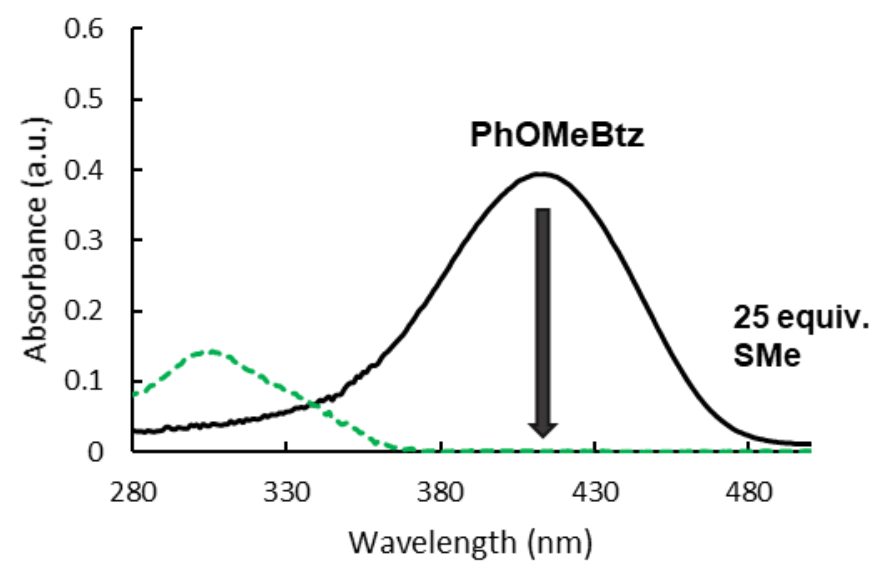

B)

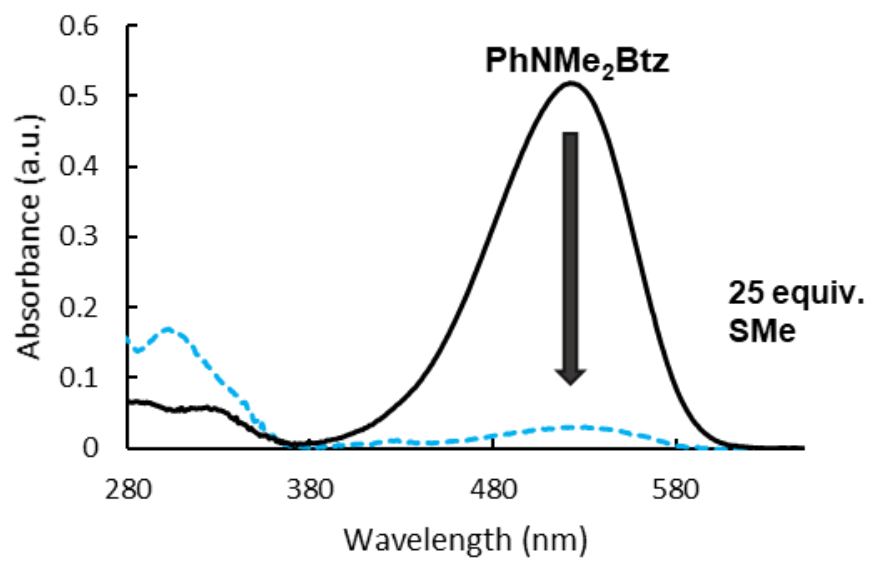

C)

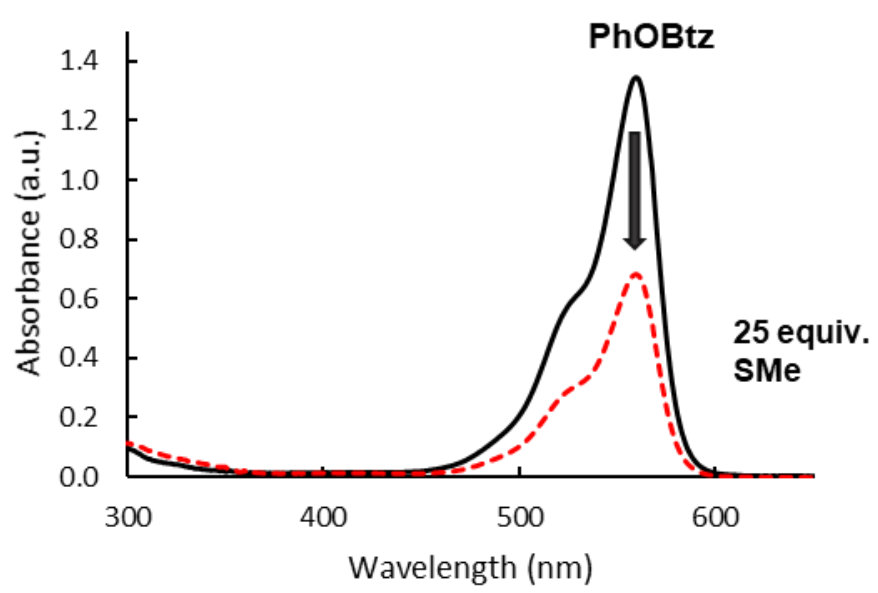

Figure S2. UV-vis absorption spectra of the merocyanine dyes $(10 \mu \mathrm{M})$ in the absence (black traces) and presence of 25 equiv. NaSMe (colored dashed traces) in 9:1 DMF: $\mathrm{H}_{2} \mathrm{O}$ at $298 \mathrm{~K}$. 


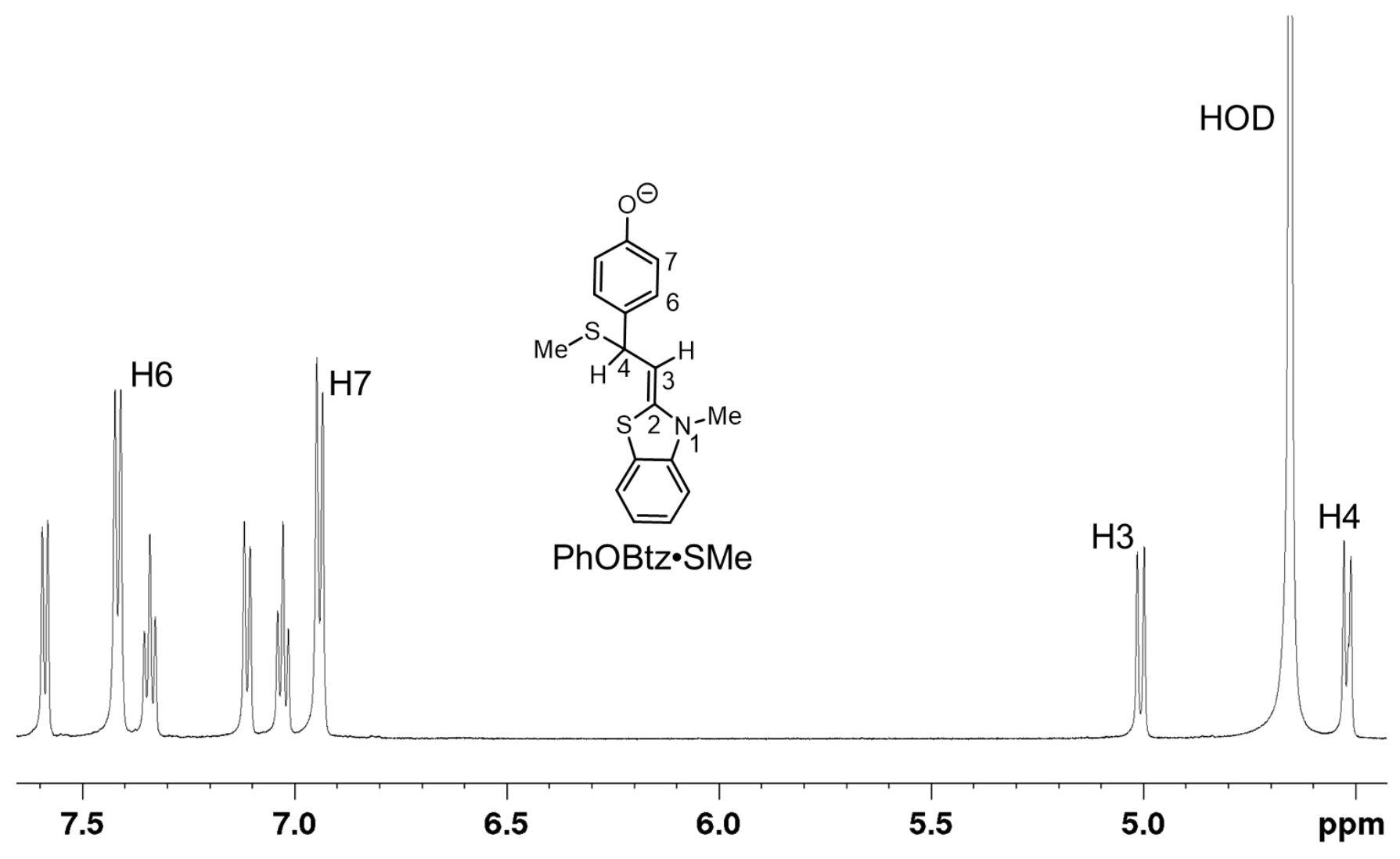

Figure S3. Downfield region of the $600 \mathrm{MHz}{ }^{1} \mathrm{H}$ NMR spectrum of PhOHBtz $(20 \mathrm{mM})$ in the presence of 5 equiv. NaSMe recorded in 9:1 DMF- $\mathrm{d}_{7}: \mathrm{D}_{2} \mathrm{O}$ at $241 \mathrm{~K}$. 

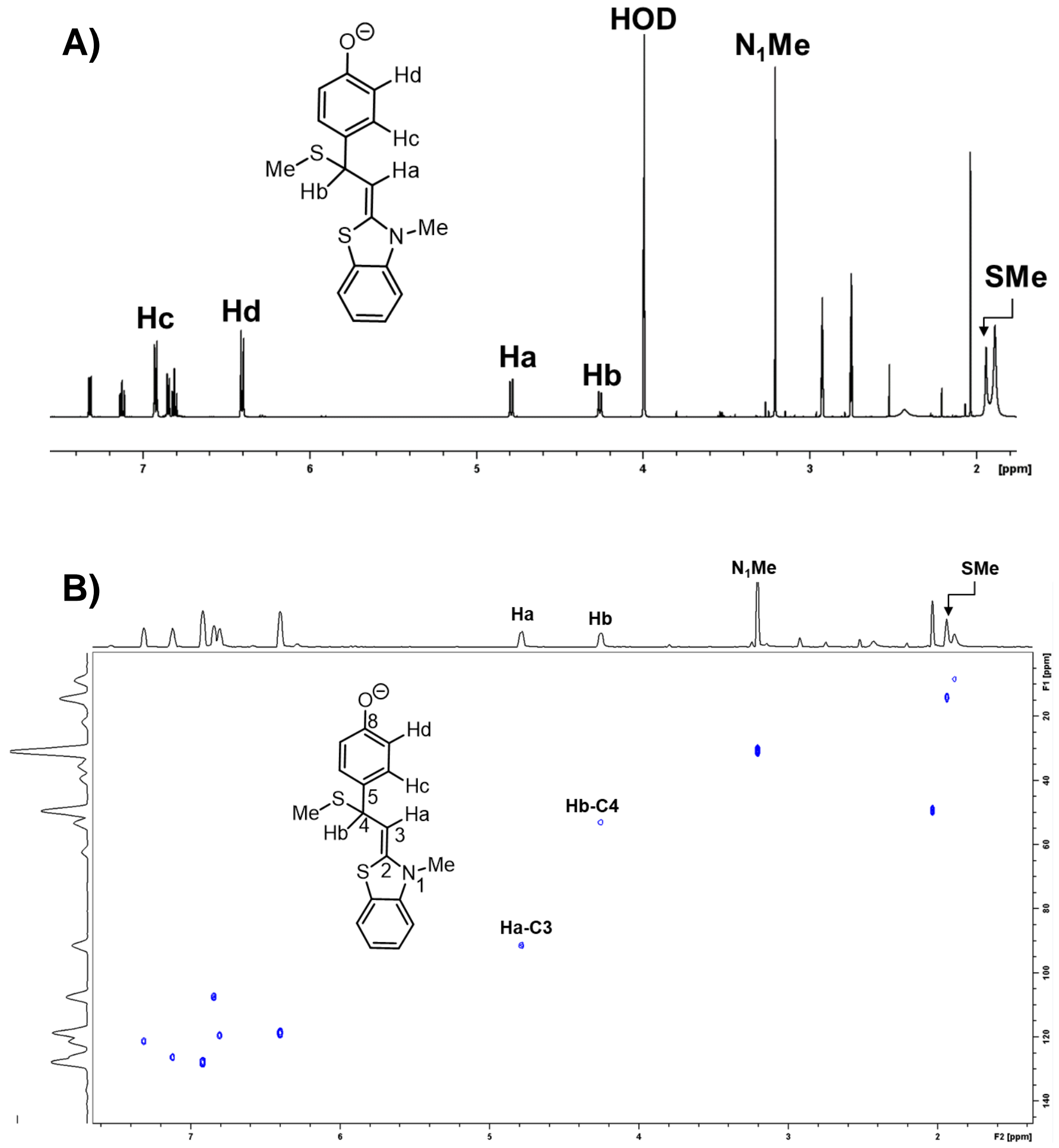


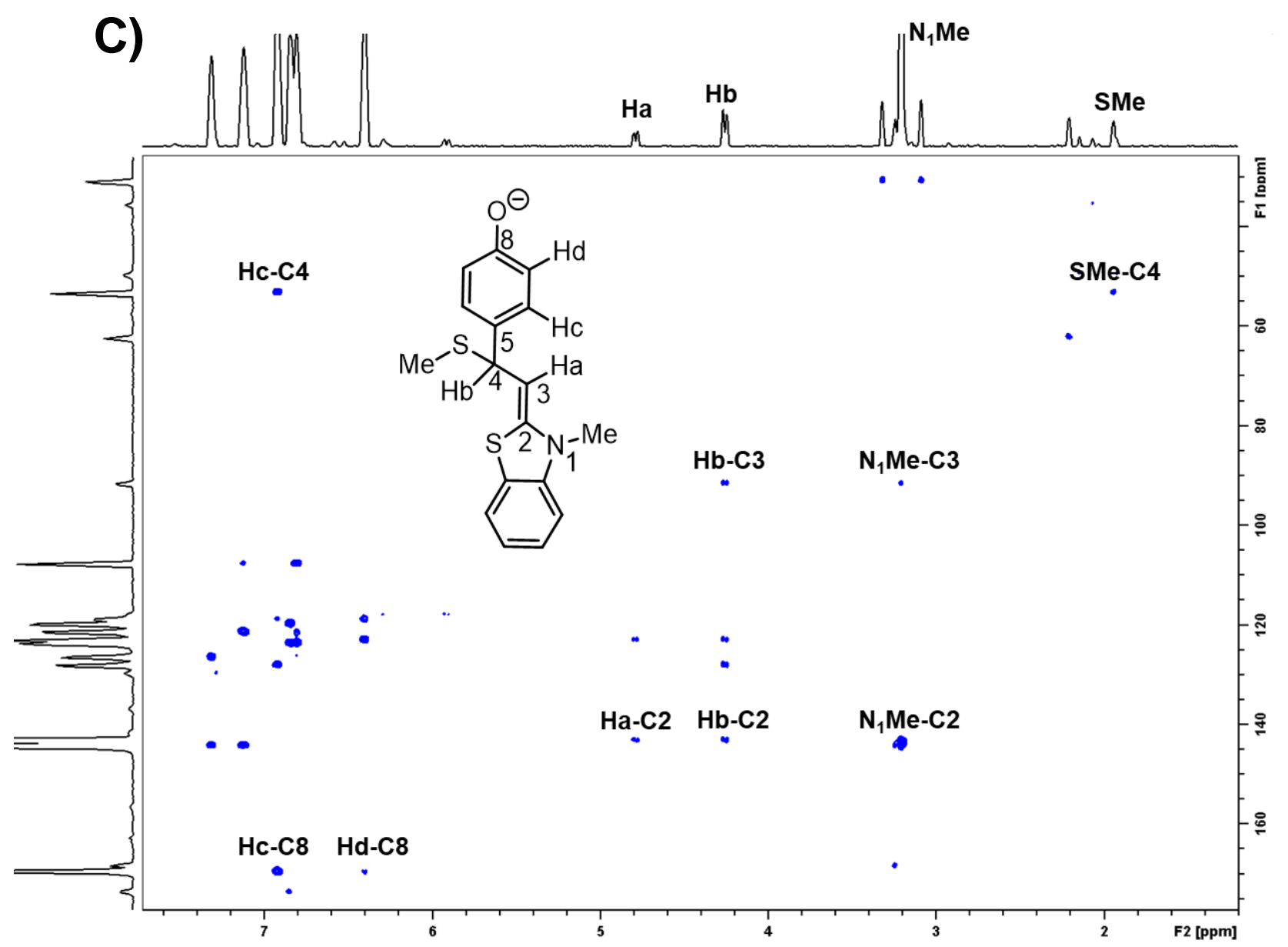

Figure S4. A) $600 \mathrm{MHz}{ }^{1} \mathrm{H}$ NMR spectrum of PhOHBtz $(20 \mathrm{mM})$ in the presence of 5 equiv. NaSMe recorded in 9:1 DMF-d7: $\mathrm{D}_{2} \mathrm{O}$ at $298 \mathrm{~K}$. B) ${ }^{1} \mathrm{H}-{ }^{13} \mathrm{C}$ HSQC spectrum highlighting ${ }^{13} \mathrm{C}$ resonances $(\mathrm{C} 4, \mathrm{C} 3)$ for $\mathrm{Ha}$ and $\mathrm{Hb}$. C) ${ }^{1} \mathrm{H}^{-13} \mathrm{C}$ HMBC spectrum revealing through-bond correlations between $\mathrm{Ha}, \mathrm{Hb}, \mathrm{Hc}, \mathrm{Hd}, \mathrm{N}_{1} \mathrm{Me}$ and $\mathrm{SMe}$ with $\mathrm{C} 8, \mathrm{C} 4, \mathrm{C} 3$ and $\mathrm{C} 2$. 

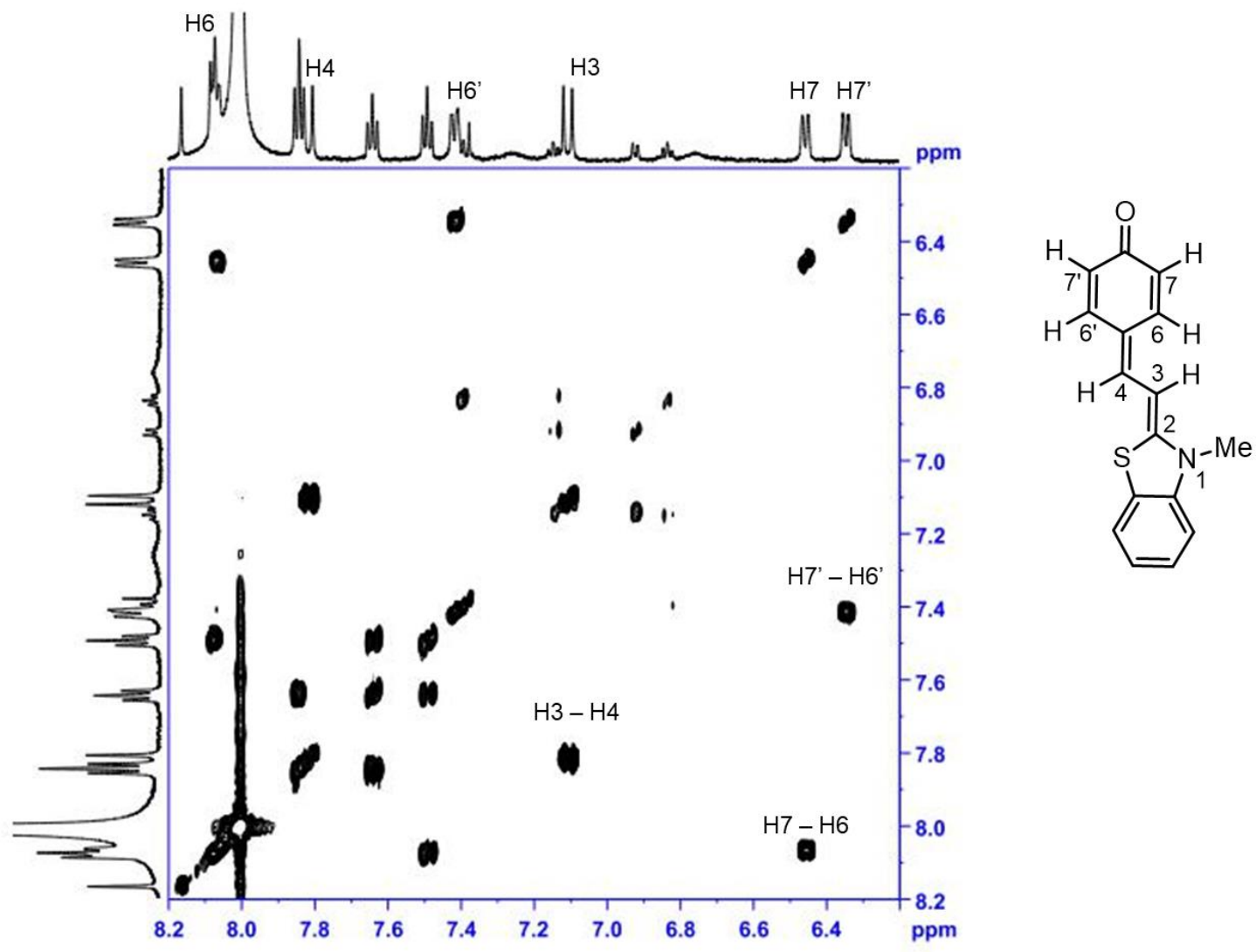

Figure S5. COSY spectrum of PhOBtz +5 equiv. NaSMe recorded in 9:1 DMF-d7: $\mathrm{D}_{2} \mathrm{O}$ at 241 $\mathrm{K}$. The major species is PhOBtz that is present in the unsymmetrical quinone methide resonance structure. Cross-peaks highlight coupling from $\mathrm{H} 7,7^{\prime}$ to $\mathrm{H6}, 6^{\prime}$ for the nonequivalent ring protons and for $\mathrm{H} 3, \mathrm{H} 4$ that are trans to each other. 


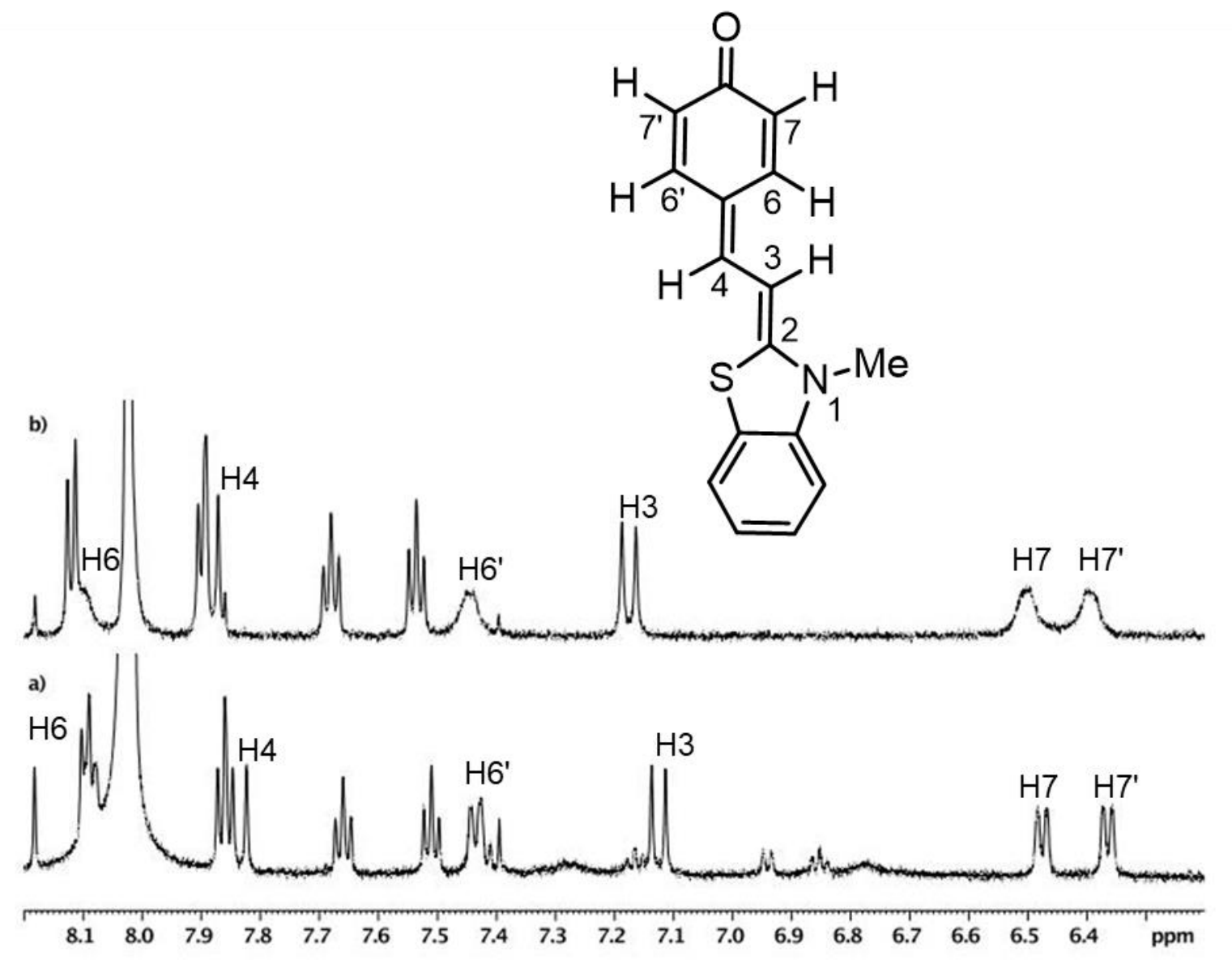

Figure S6. a) Downfield region of the $600 \mathrm{MHz}{ }^{1} \mathrm{H}$ NMR spectrum of PhOHBtz (1 mM) in the presence of 5 equiv. NaSMe recorded in 9:1 DMF-d7:D2O at $241 \mathrm{~K}$. b) Same spectral region of the ${ }^{1} \mathrm{H}$ NMR spectrum of PhOHBtz $(1 \mathrm{mM})$ in the presence of excess $\mathrm{Na}_{2} \mathrm{CO}_{3}$ in 9:1 DMF- $\mathrm{d}_{7}: \mathrm{D}_{2} \mathrm{O}$ at $231 \mathrm{~K}$. 


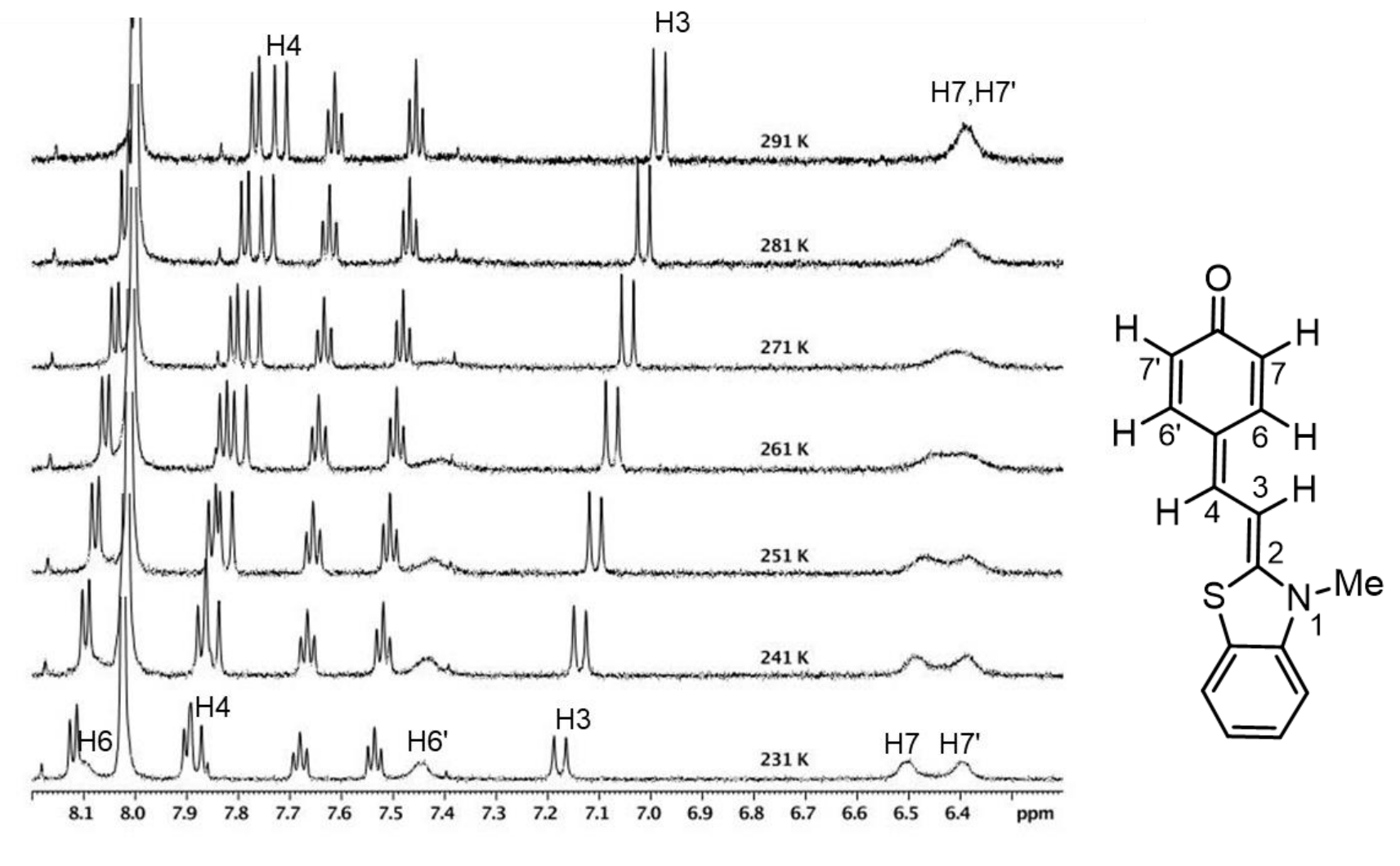

Figure S7. Downfield region of the $600 \mathrm{MHz}{ }^{1} \mathrm{H}$ NMR spectrum of PhOHBtz (1 mM) in the presence of excess $\mathrm{Na}_{2} \mathrm{CO}_{3}$ in 9:1 DMF- $\mathrm{d}_{7}: \mathrm{D}_{2} \mathrm{O}$ as a function of temperature. The nonequivalent $\mathrm{H} 6, \mathrm{H} 7$ protons for the quinone methide resonance structure are clearly visible from $231-251 \mathrm{~K}$. However, at $281 \mathrm{~K}$ the $\mathrm{H} 7, \mathrm{H} 77^{\prime}$ protons have merged into a single broad peak and the $\mathrm{H} 6, \mathrm{H}^{\prime}$ protons have broadened into the baseline and are not visible. As the temperature is increased $\mathrm{H} 3$ and $\mathrm{H} 4$ shift upfield. 


\section{\begin{tabular}{l|l} 
Temp & PhOBtzoSMe:PhOBtz
\end{tabular}}

\begin{tabular}{l|l}
$241 \mathrm{~K}$ & $1: 3.6$
\end{tabular}

\begin{tabular}{l|l}
$303 \mathrm{~K}$ & $1: 10.4$
\end{tabular}

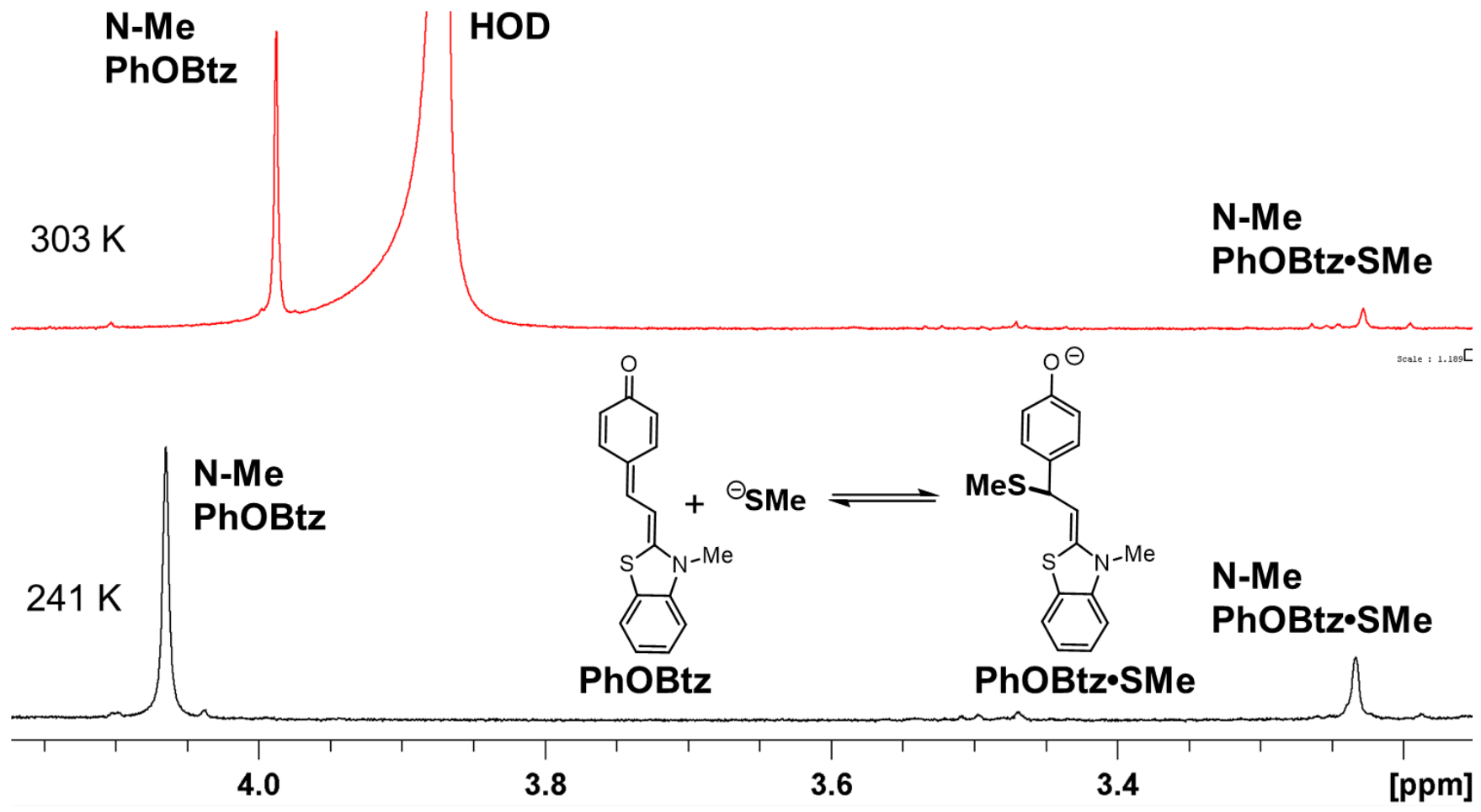

Figure S8. N-Me region of ${ }^{1} \mathrm{H}$ NMR spectra $\left(600 \mathrm{MHz}, 9: 1 \mathrm{DMF}-\mathrm{d}_{7}: \mathrm{D}_{2} \mathrm{O}\right)$ for the $5: 1$ sample of NaSMe:PhOHBtz (1 mM) at $241 \mathrm{~K}$ (lower black trace) vs. $303 \mathrm{~K}$ (upper red trace). The table provides the relative ratio (determined by peak integration) of the two $\mathrm{N}$-Me resonances $(4.07$ ppm for PhOBtz and $3.25 \mathrm{ppm}$ for PhOBtz•SMe) at $241 \mathrm{~K}$ vs. $303 \mathrm{~K}$. 

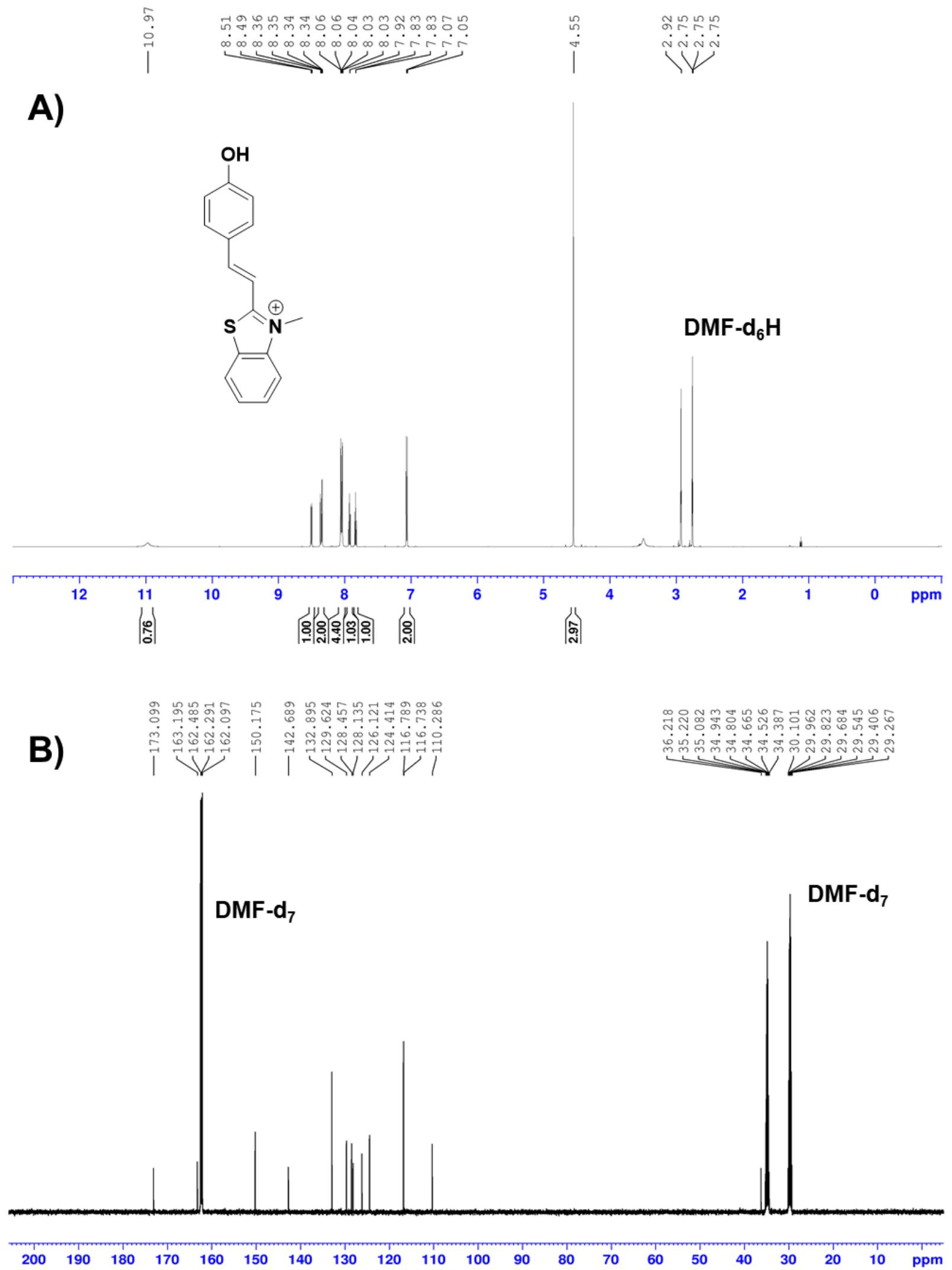

Figure S9. A) $600 \mathrm{MHz}{ }^{1} \mathrm{H}$ NMR spectrum of PhOHBtz (20 mM) in DMF-dz at $25^{\circ} \mathrm{C}$. B) 150 $\mathrm{MHz}{ }^{13} \mathrm{C}\left\{{ }^{1} \mathrm{H}\right\}$ NMR spectrum of PhOHBtz in DMF-d 7 at $25^{\circ} \mathrm{C}$. 
A)
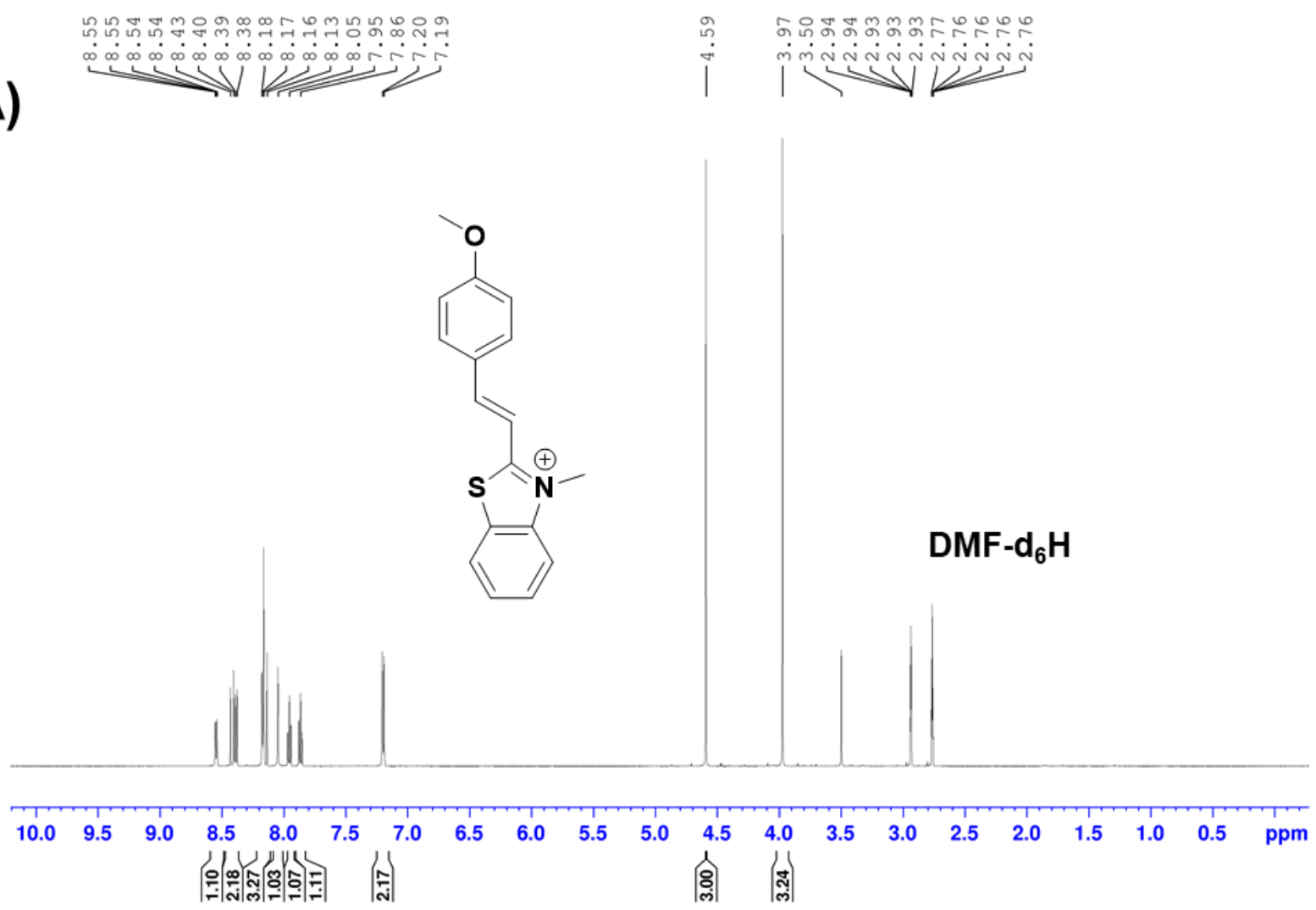

B)
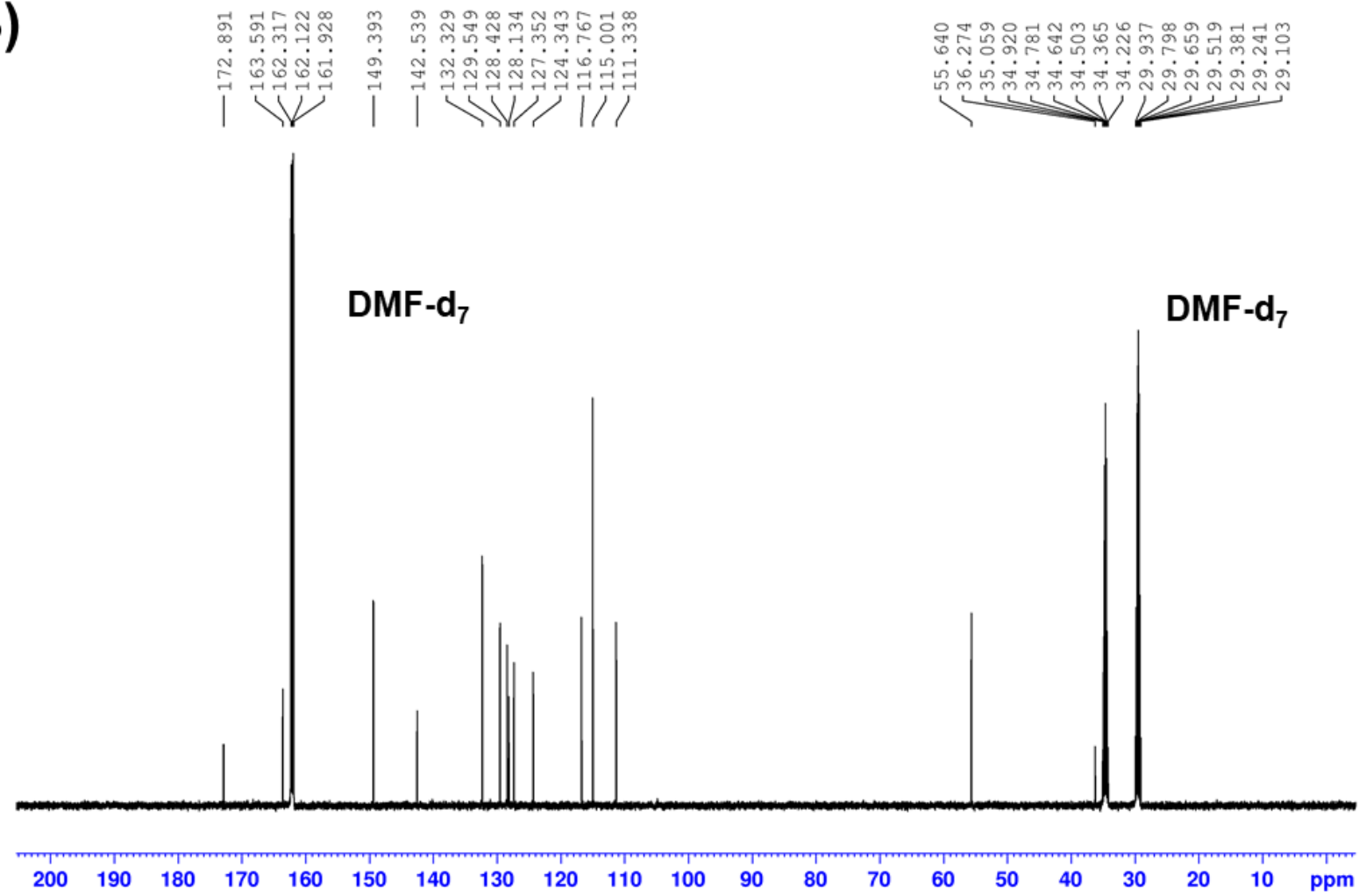

Figure S10. A) $600 \mathrm{MHz}{ }^{1} \mathrm{H}$ NMR spectrum of PhOMeBtz (20 mM) in DMF-d7 at $25^{\circ} \mathrm{C}$. B) 150 $\mathrm{MHz}{ }^{13} \mathrm{C}\left\{{ }^{1} \mathrm{H}\right\}$ NMR spectrum of PhOMeBtz in DMF-d7 at $25^{\circ} \mathrm{C}$. 


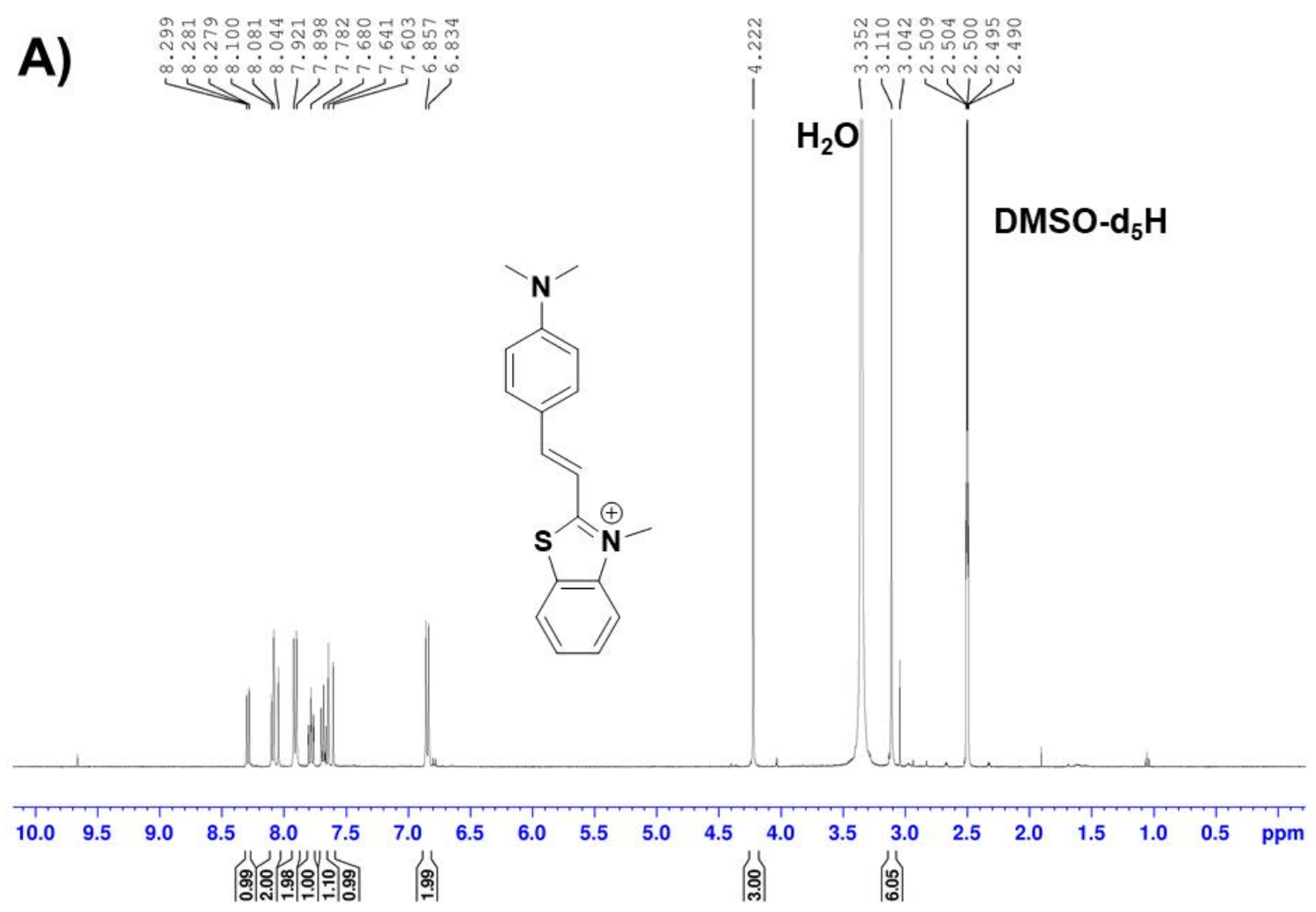

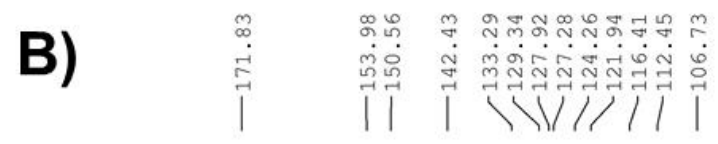

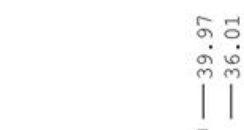

DMSO-d 6

Figure S11. A) $400 \mathrm{MHz}{ }^{1} \mathrm{H}$ NMR spectrum of PhNMe $2 \mathrm{Btz}$ in DMSO-d6. B) $100 \mathrm{MHz}{ }^{13} \mathrm{C}\left\{{ }^{1} \mathrm{H}\right\}$ NMR spectrum of $\mathrm{PhNMe}_{2} \mathrm{Btz}$ in DMSO-d6. 


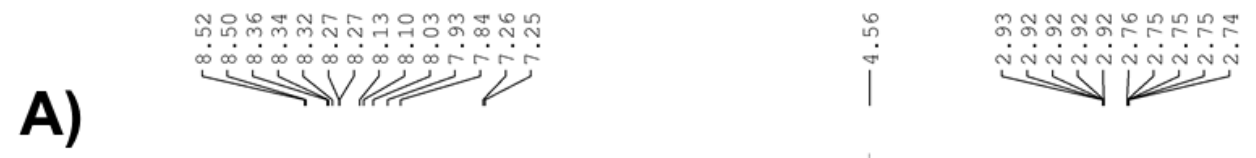
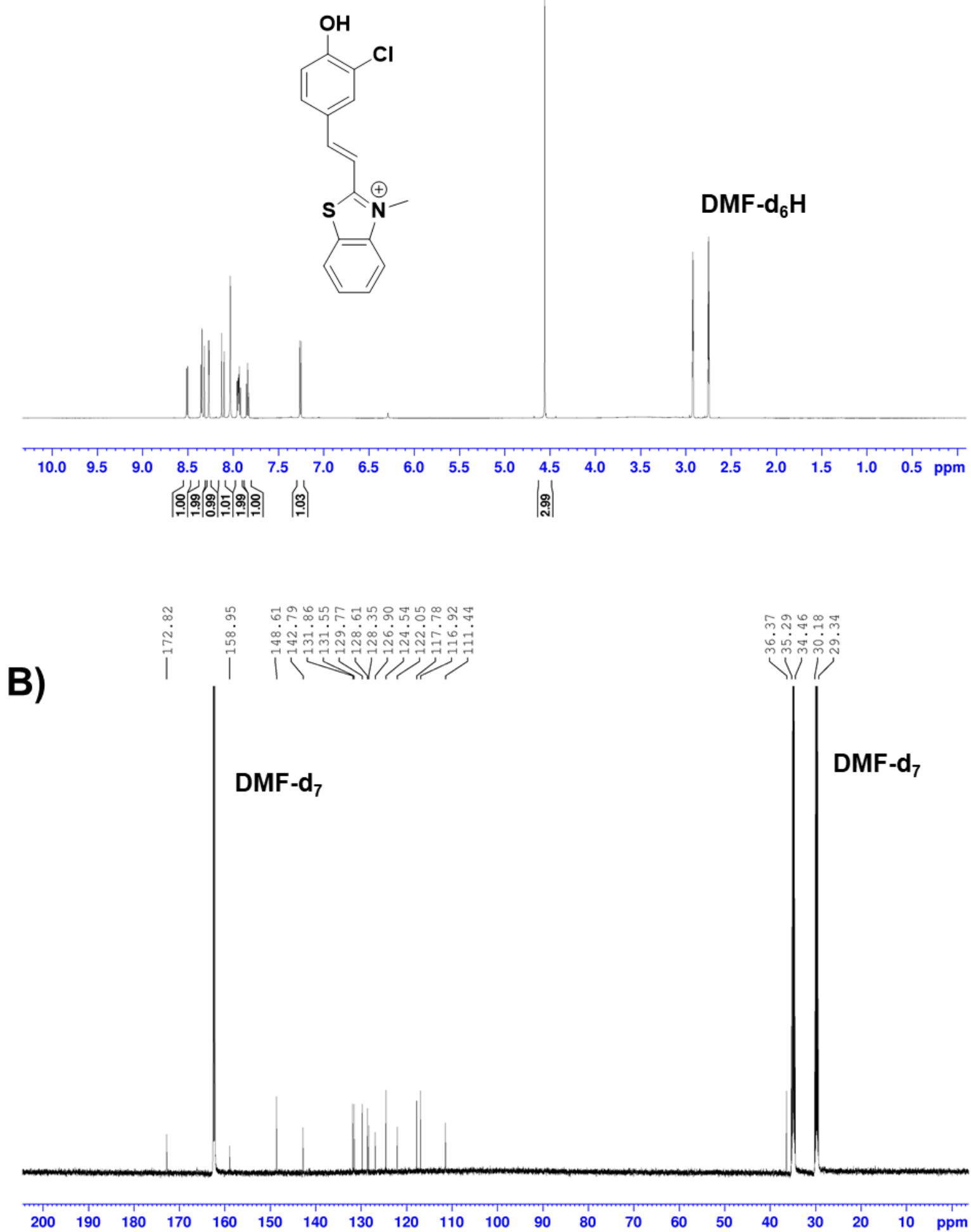

Figure S12. A) $600 \mathrm{MHz}{ }^{1} \mathrm{H}$ NMR spectrum of CIPhOHBtz (20 mM) in DMF-d7 at $25^{\circ} \mathrm{C}$. B) 150 $\mathrm{MHz}{ }^{13} \mathrm{C}\left\{{ }^{1} \mathrm{H}\right\}$ NMR spectrum of CIPhOHBtz in DMF-d7 at $25^{\circ} \mathrm{C}$. 
A)
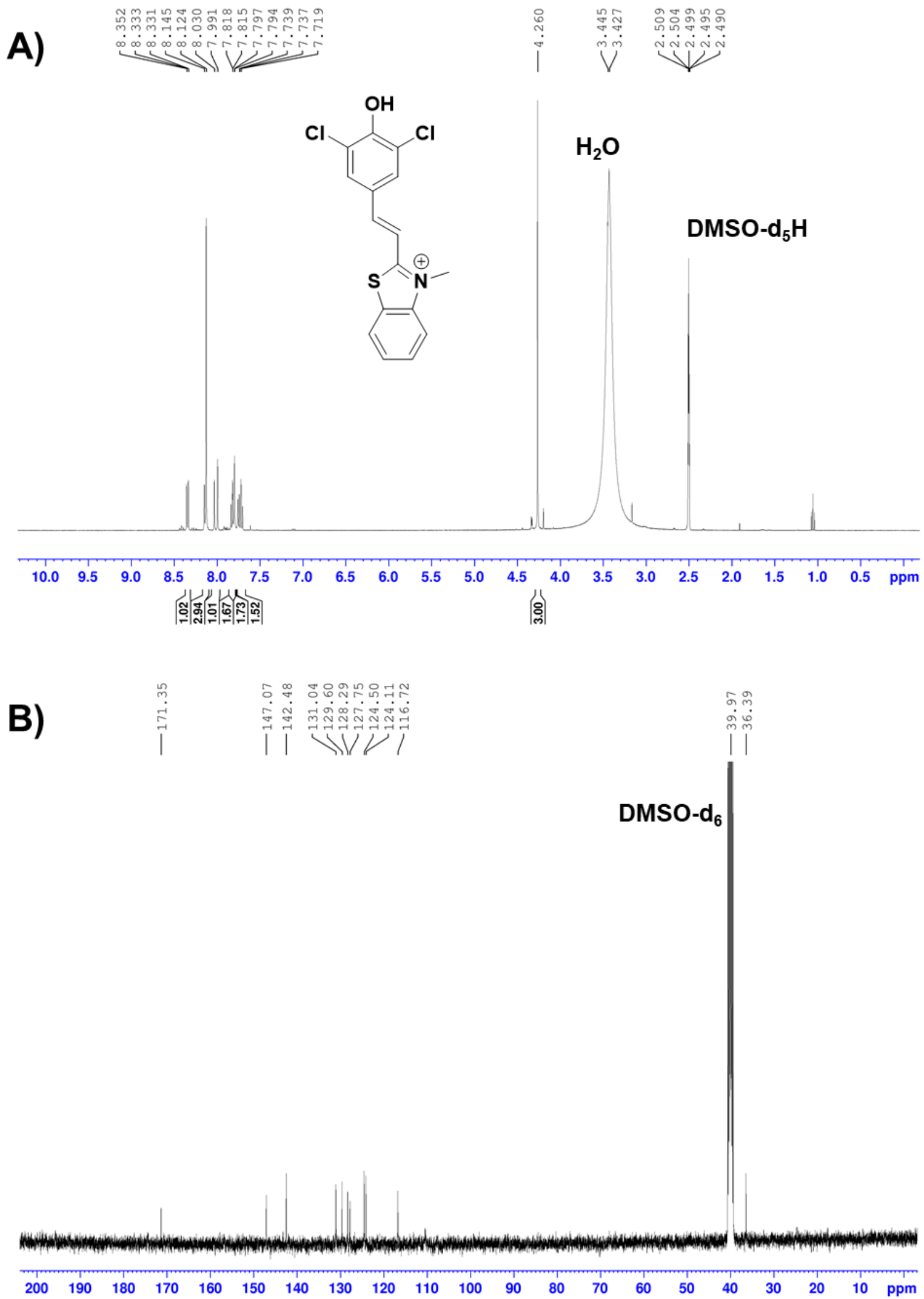

Figure S13. A) $400 \mathrm{MHz}{ }^{1} \mathrm{H}$ NMR spectrum of $\mathrm{Cl}_{2} \mathrm{PhOHBtz}$ in DMSO-d6. B) $100 \mathrm{MHz}{ }^{13} \mathrm{C}\left\{{ }^{1} \mathrm{H}\right\}$ NMR spectrum of $\mathrm{Cl}_{2} \mathrm{PhOHBtz}$ in DMSO-d6. 